Heat Pipe Science and Technology: An International Journal 8(1):v-vi (2017)

\title{
PREFACE: SELECTED PAPERS FROM THE JOINT 18TH INTERNATIONAL HEAT PIPE CONFERENCE AND THE 12TH INTERNATIONAL HEAT PIPE SYMPOSIUM
}

This special issue is composed of five papers presented at the Joint 18th International Heat Pipe Conference and the 12th International Heat Pipe Symposium (Joint 18th IHPC and 12th IHPS), which were held in Ramada Plaza hotel, Jeju, Korea, during June 12-16, 2016. This conference was organized by Heat Pipe Committee of the Korean Society of Mechanical Engineers (KSME). More than 240 participants, sponsors, and exhibitors from 24 countries around the world attended the conference. Altogether 144 technical papers were presented in the technical sessions which included the most up-to-date technologies associated with heat pipes.

The topics of the four papers submitted include design, manufacturing, and characterization of copper capillary structures for loop heat pipes (Remi Giraudon et al.), innovative thermal design satellite with networked variable conductance oscillating heat pipes (Naoko Iwata et al.), fluid flow and heat transfer characteristics of a JEST-type loop thermosyphon (Ayaka Suzuki et al.) and effect of the condenser temperature on the start-up of a pulsating heat pipe (Daniele Mangini et al.).

Special thanks are due to the authors of the papers in this special issue. These authors have worked diligently in meeting the review schedule and responding to the reviewers' comments. Our sincere thanks also go to the excellent reviewers who have provided valuable comments to the authors.

We think that the special issue is the result of close collaboration between the Editorial Committee of the Heat Pipe Science and Technology, An International Journal and the Guest Editors from the Organizing Committee of Joint 18th IHPC and 12th IHPS. Therefore, we would like to say thanks the Editorial Committee of the HPST, An International Journal and also Begell House, Inc. for supporting review and publication process.

In closing, we would like to express gratitude to Conference Chair, Prof. Joon Hong Boo of Korea Aerospace University, Co-Chairs, Dr. Young Soo Lee of Korea Institute of Energy Research and Dr. Kwang-Soo Kim of Apack Inc., and Secretary General, Prof. Seok Ho Rhi of Chungbuk National University, for their passion and devotion to heat pipe science that made the conference the most successful one ever. 
Seok Hwan Moon

IT New Material Research Group

Electronic Telecommunication and Research Institute

Korea

Marcia Barbosa Henriques Mantelli

Federal University of Santa Catarina

Florianopolis, Brazil 